\title{
Using Multi-Slice Computed Tomography In Age Estimation Based on the Fusion of the Sternal Elements among Group of Egyptian Subjects
}

\author{
Eman Ahmed Alaa El-Din, Heba El Sayed Mostafa and Sameh Saber ${ }^{1}$
}

\footnotetext{
${ }^{1}$ Departments of Forensic Medicine \& Clincal Toxicolcogy and Radiodiagnosis, Faculty of Medicine, Zagazig University,AL Sharqia, Egypt.
}

\begin{abstract}
Objectives: Determination of age from human skeletal remains for forensic and medico-legal purpose is an important matter in civil and criminal cases. Radiological examination of sternum especially fusion of sternal segments offer considerable help. Computed tomography (CT) is rapidly becoming the gold standard for analysis of skeletal and dental development in both clinical and increasingly, in forensic practice. The purpose of the present study was to estimate age from the assessment of the degree of fusion of xiphoid process and manubrium with mesosternum using the utility of multi-slice C $\mathrm{T}$. Subjects and Methods: The study includes 100 subjects consisting of 49 males and 51 females. The age groups included in the study ranged from 30 to $6^{\circ}$ years (yrs). The fusion status of xiphoid process and manubrium with the mesosternum were evaluated for degree of fusion: complete, partial, absent by using multislice CT scan. Results: fusion of xiphoid with mesosternum In male and female groups, began after $30 \mathrm{yrs}$ of age but the fusion was not complete within 30 to 40 yrs. From 45 up to 55 yrs, closure was invariable with different degrees. From the age of 55 up to 65 yrs, all subjects showed complete fusion. Complete fusion started earlier in female group (at 35 to 40 yrs) than in male group that began (at 40 to $45 \mathrm{yrs}$ ). While fusion of manibrium with mesosternum in male group began after 45 yrs of age. The fusion was invariable in the age from 50 up to 60 yrs old. From the age of 60 to 65 yrs all subjects showed complete fusion. In female group partial fusion began from 40 up to 45 yrs of age. In the age from above 45 to $60 \mathrm{yrs}$ the fusion was invariable. From the age of 60 to 65 yrs all subjects showed complete fusion. It was also noticed that partial fusion started earlier in female group ( at 40 yrs ) than in male group that began (at $45 \mathrm{yrs}$ ). Conclusion: From the previous results it can be concluded that applicating multi-slice CT- based age diagnostics assessment of the degree of fusion of the xiphoid process and manubrium with mesosternum could be helpful in estimation of age. The fusion of the xiphoid process with the mesosternum began after the age of thirty. The fusion was present in uneven degrees up to the age of forty-five. In most of subjects the fusion is complete after the age of fifty. The fusion of the manubrium with the mesosternum began after the age of forty. The fusion was present in varying degrees in subjects above fifty five years. Complete fusion, when present, occurs after the age of fifty. All these data could be helpful in determination of age from sternal bone.
\end{abstract}

Keywords Age estimation, sternum, manubrium, xiphoid, multislice CT scan.

\section{Introduction}

A ge estimation of unidentified human skeletal remains is one of the many objectives, required to be achieved not only in forensic practice but also in physical anthropology for the purposes of identification. The changes of developmental processes like epiphysealediaphyseal union, as well as those of the degenerative processes like dental attrition are useful for estimation of age of 
such skeletal remains. Both these developmental and degenerative processes affect different anatomical structures of the human body at different stages of life in a more or less regular and recognizable pattern depending on the stage of life and the anatomical region being observed (Singh \& Chavali, 2011).

Determination of age is an important forensic matter in many civil and criminal cases. It could be difficult for doctors to assess the age with reasonable degree of error (Gupta et al., 2007). Different aging methods are available for different anatomical regions of the human body like dentition, epiphysealediaphyseal union, cranial suture closure, morphology of the auricular surface of ilium, fusion of sternal and sacral elements and phase analysis of sternal end of ribs; but due to destructive taphonomic processes, few or none of these age diagnostic features of bones may be available for analysis in archaeological, palaeontological or forensic materials, thus making it essential to develop reliable aging methods (Menezes et al., 2011).

Sternum has been used by researchers for estimation of sex and stature and to provide valuable clues on the age of the deceased. A sternum comprises of three distinct parts: a manubrium superiorly, a mesosternum or the main body in the middle, and a xiphoid process placed inferiorly. The manubrium joins with mesosternum by a primary or secondary cartilaginous joint (manubrio-mesosternal junction), and the xiphoid similarly unites with the mesosternum by either a primary or a secondary cartilaginous joint (mesosterno-xiphisternal junction). The ossification of human skeleton follows definite timings of appearance as well as fusion. Age estimation from sternum is, thus, based upon the analysis of the fusion of manubrium with mesosternum and fusion of xiphoid with mesosternum as well on the morphological characteristics of sternum (Atal et al., 2008).

In the past 10 years, publications regarding forensic imaging have increased dramatically. This reflects the increasing number of forensic institutes with an associated radiological facility including a computed tomography (CT) and/or a magnetic resonance imaging (MRI) scanner (Tangmose et al., 2013).

Radiological examination of sternum especially fusion of sternal segments, fusion of manibrum and xiphoid process with mesosternum offer considerable help. However, traditional or digital X-rays have limitations like one have to take more than one views and there is always possibility of overlapping of the thoracic tissue shadow (Tailor et al., 2013).

Computed tomography (CT) is preferred than conventional radiography for identification and age determination. It also provides a clear appreciation of the anatomical areas of interest without the inconvenience of superimposition of other structures which can compromise accurate interpretation, and is capable of discerning finer detail than is possible with conventional radiography (O’Donnell et al., 2011).

The present study aimed to estimate the age from the assessment of the degree of fusion of the xiphoid process and manubrium with mesosternum using the means of multi- slice CT scan.

\section{Subjects and Methods}

One hundred $\mathrm{C} T$ examinations, with proven age chronological ranging from (30 to $6^{\circ}$ yrs) originally obtained from patients who were referred for thoracic CT examination for various clinical reasons at the period between July 2013 and June 2014 then examined retrospectively. Since the Multidetector computed tomography (MD.CT.) scans emerged during thoracic CT examination diagnostic procedures at the out private clinics.

\section{Ethical consideration of the study}

The following study was approved by the local Ethics Committee of Faculty of Medicine and radiology center manager. Also, confidentiality of the patient's records were kept.

\section{Exclusion criteria}

Computed tomography images of Patient having thoracic skeletal deformity, trauma or any diseases affecting skeletal development and whose ages below 30 or above 65 years old were excluded from the study.

This study group consisted of 51 female and 49 male subjects, aged between 30 and 65 years that permitted reliable examination. The xiphisternal and manubriosternal regions were carefully visualized by utilizing spiral multislice CT machine (Philips inguinity 128 slice CT) and 4-row (MDCT) system (Toshiba astion japan). Technical settings, $120 \mathrm{kV}$, reference mAs 120 200 using Care Dose, pitch 1.3, collimation 0.6, reconstruction increment 1.0, kernel B50f. Due to the fact that all the scans analyzed were based on high resolution thin-slice MDCT imaging, it can be assumed that the scans provided a comparable and sufficient image quality with regard to the evaluation of osseous structures.

The CT images were evaluated on screen using a workstation. The material was viewed in axial, coronal and sagittal images, multi-planar reconstruction (MPR) and maximum intensity projection (MIP) techniques. The fusion status of xiphoid process and manubrium with the mesosternum were evaluated by using the classification stages of Kaneriya et al. (2013) as follow:

Grade I: Non fusion

Grade II: Partial fusion

Grade III: Complete fusion. 
Table (1): Chronological age distribution of male and female subjects examined in the study (no=100).

\begin{tabular}{|l|l|l|l|l|}
\hline \multirow{2}{*}{$\begin{array}{l}\text { Chronogical } \\
\text { age (years) }\end{array}$} & \multicolumn{2}{|l|}{ Female } & Male \\
\cline { 2 - 5 } & No. & \% & No. & \% \\
\hline $30-$ & 10 & 19.6 & 10 & 20.4 \\
\hline $35-$ & 5 & 9.8 & 7 & 14.3 \\
\hline $40-$ & 7 & 13.7 & 9 & 18.4 \\
\hline $45-$ & 9 & 17.6 & 8 & 16.3 \\
\hline $50-$ & 6 & 11.8 & 7 & 14.3 \\
\hline $55-$ & 6 & 11.8 & 6 & 12.2 \\
\hline $60-65$ yrs & 5 & 9.8 & 3 & 6.1 \\
\hline Total & 51 & 100.0 & 49 & 100.0 \\
\hline
\end{tabular}

\section{Results}

The present study includes 100 subjects consisting of 49 male and 51 female. The age groups included in the study ranged from 30 yrs to 65 yrs (Table-1).

a) Fusion status of xiphoid process with the mesosternum in male and female groups respectively(Table-2,3)

In male group, it was observed that fusion began after 30 yrs of age (30\% of subjects showed partial fusion and $70 \%$ without any fusion (figure-1). In the age from above 35 to $40 \mathrm{yrs}$ (28.8\% of subjects showed partial fusion and $71.4 \%$ without any fusion). In the age from above 40 to 45 yrs $55.6 \%$ subjects had complete fusion between xiphoid and mesosternum (figure-3) while $33.3 \%$ showed partial fusion and nonfusion in $11.1 \%$. In the age from above 45 up to $50 \mathrm{yrs}$, $75 \%$ of subjects showed complete fusion while only $25 \%$ with partial fusion. At the age from above 50 up to $55 \mathrm{yrs}, 71.4 \%$ of subjects showed complete fusion, $14.3 \%$ partial fusion and $14.3 \%$ appeared without any fusion. From the age of 55 up to 65 yrs, all subjects $(100 \%)$ showed complete fusion (Table-2) (figure-3).

There was a high significant difference $(\mathrm{p}<$ 0.01 ) at age group 55-60 yrs, while, there was a significant difference $(\mathrm{p}<0.05)$ at age group 30-35,35$40,45-50,50-55 \& 60-65$ yrs and there was no significant difference $(\mathrm{p}>0.05)$ at age group 40-45 yrs (Table- 2).

In female group it was noted that fusion began after 30 yrs of age (20\% of subjects showed partial fusion and $80 \%$ without any fusion). In the age group from above 35 to $40 \mathrm{yrs}, 20 \%$ of subjects showed complete fusion, $60 \%$ with partial fusion and $20 \%$ without fusion. In the age group from above 40 to $45 \mathrm{yrs}, 28.6 \%$ of subjects showed complete fusion, $57.1 \%$ with partial fusion (figure-2) and $14.3 \%$ without fusion. In the age group from above 45to 50 yrs, $66.7 \%$ of cases showed complete fusion, $25.0 \%$ with partial fusion and $12.5 \%$ without fusion. In the age group from above 50to $55 \mathrm{yrs}, 83.3 \%$ of cases showed complete fusion, $16.7 \%$ with partial fusion and
$14.3 \%$ without any fusion. From the age of 55 to $65 \mathrm{yrs}$ all subjects showed complete fusion $100 \%$ (Table-3).

There was a high significant difference $(\mathrm{p}<$ 0.01 ) at age group $30-35,55-60 \& 60-65$ yrs. Also, there was a significant difference $(\mathrm{p}<0.05)$ at age group 45-50, 50-55 yrs. While, there was no significant difference $(p>0.05)$ at age group 35-40\& 40-45 yrs (Table-3).

b) Fusion status of manibrium with the mesosternum in male and female respectively(Table-4,5)

In male group, fusion couldn't be detected from the age of 30 up to 40 yrs. Fusion began after 45 yrs of age (12.5\% with partial fusion (figure-5) and $87.5 \%$ without fusion). In the age from above 50 to 55 yrs, $16.7 \%$ of subjects had complete fusion between manibrium and mesosternum while 50\% showed partial fusion and $33.3 \%$ without fusion. In the age group from above 55to 60 yrs, $50.0 \%$ of subjects showed complete fusion, $33.3 \%$ with partial fusion and $16.7 \%$ without any fusion. From the age of 60 to 65 yrs, all subjects $(100 \%)$ showed complete fusion $($ Table-0) (figure-6)

There was a high significant difference $(\mathrm{p}<$ 0.01 ) at age group 30-35, 35-40, 40-45, 45-50 yrs. Also, there was a significant difference $(\mathrm{p}<0.05)$ at age group 60-65 yrs while, was no significant difference $(\mathrm{p}>0.05)$ at age group 50-55\& 55-60 yrs (Table-5).

In female group it was noted that fusion delayed up to 40 yrs (figure-4). Partial fusion (14.3\%) began from 40 up to 45 years of age (figure-7). In the age from above 45 to 50 years $25 \%$ of subjects showed partial fusion and $75.0 \%$ without fusion. Complete fusion $(33.3 \%)$ started at the age of 50 up to 55 years that also showed partial fusion in $66.7 \%$ of subjects. In the age group from above 55to 60 years, $50.0 \%$ of subjects showed complete fusion, $50.0 \%$ with partial fusion. From the age of 60 to 65 years all cases showed complete fusion $100 \%$ (Table-6).

There was a high significant difference $(\mathrm{p}<$ 0.01 ) at age group 30-35, 35-40, 45-50, 60-65 yrs . Also, there was a significant difference $(p<0.05)$ at age group 40-45, 50-55 yrs and there was no significant difference $(p>0.05)$ at age 55-60 yrs (Table-6).

All the subjects below the age of the 40 yrs did not show either complete or partial fusion of the manubrium with mesosternum. In cases above 45 yrs of age, pattern of fusion is tabulated as shown in (Table 5\& 6). No subject had been recorded with complete fusion below 50 yrs of age. While above 60 yrs fusion was complete (figure-8). There was no significant difference between males and females groups as regard fusion status of xiphoid process or manubrium with the mesosternum in all age groups (Table 4\&7) 
Table-2: Chi-Square statistical analysis $\left(\mathrm{X}^{2}\right.$-test) of fusion status in males (xiphoid with the mesosternum) at different age groups of the study.

\begin{tabular}{|l|l|l|l|l|l|l|l|l|l|}
\hline \multirow{2}{*}{$\begin{array}{c}\text { Age } \\
\text { group }\end{array}$} & \multirow{2}{*}{$\begin{array}{c}\text { No of } \\
\text { cases }\end{array}$} & \multicolumn{2}{|c|}{ Complete } & \multicolumn{2}{c|}{ Partial } & \multicolumn{2}{c|}{ Absent } & \multirow{2}{*}{ X2 } & \multirow{2}{*}{ P.value } \\
\cline { 2 - 9 } & No. & $\mathbf{\%}$ & No. & \% & No. & \% & & \\
\hline $30-$ & 10 & 0 & 0.0 & 3 & 30.0 & 7 & 70.0 & 11.1 & $0.004^{*}$ \\
\hline $35-$ & 7 & 0 & 0.0 & 2 & 28.8 & 5 & 71.4 & 8.14 & 0.017 \\
\hline $40-$ & 9 & 5 & 55.6 & 3 & 33.3 & 1 & 11.1 & 4.0 & 0.135 \\
\hline $45-$ & 8 & 6 & 75.0 & 2 & 25.0 & 0 & 0.0 & 10.5 & 0.005 \\
\hline $50-$ & 7 & 5 & 71.4 & 1 & 14.3 & 1 & 14.3 & 6.86 & $0.032^{*}$ \\
\hline $55-$ & 6 & 6 & 100.0 & 0 & 0.0 & 0 & 0.0 & 18.0 & $<0.001^{* *}$ \\
\hline $60-65$ & 3 & 3 & 100.0 & 0 & 0.0 & 0 & 0.0 & 9.0 & $0.011^{*}$ \\
\hline Total & 49 & 25 & 51.0 & 11 & 22.4 & 13 & 26.5 & & \\
\hline
\end{tabular}

Table-3: Chi-Square statistical analysis $\left(\mathrm{X}^{2}\right.$-test) of fusion status in females (xiphoid with the mesosternum) at different age groups of the study.

\begin{tabular}{|c|c|c|c|c|c|c|c|c|c|}
\hline \multirow[t]{3}{*}{ Age group } & \multicolumn{7}{|c|}{ No of subjects showing fusion } & \multirow{3}{*}{$\mathbf{X} 2$} & \multirow{3}{*}{ P.valu } \\
\hline & \multirow[t]{2}{*}{ No of cases } & \multicolumn{2}{|c|}{ Complete } & \multicolumn{2}{|c|}{ Partial } & \multicolumn{2}{|c|}{ Absent } & & \\
\hline & & No. & $\%$ & No. & $\%$ & No. & $\%$ & & \\
\hline $30-$ & 10 & 0 & 0.0 & 2 & 20.0 & 8 & 80.0 & 15.6 & $<0.001^{* *}$ \\
\hline $35-$ & 5 & 1 & 20.0 & 3 & 60.0 & 1 & 20.0 & 2.4 & 0.301 \\
\hline $40-$ & 7 & 2 & 28.6 & 4 & 57.1 & 1 & 14.3 & 3.0 & 0.223 \\
\hline $45-$ & 9 & 6 & 66.7 & 2 & 25.0 & 1 & 12.5 & 7.0 & $0.03^{*}$ \\
\hline $50-$ & 6 & 5 & 83.3 & 1 & 16.7 & 0 & 14.3 & 10.5 & $0,005^{*}$ \\
\hline $55-$ & 6 & 6 & 100.0 & 0 & 0.0 & 0 & 0.0 & 18.0 & $<0.001^{* *}$ \\
\hline $60-65$ & 5 & 5 & 100.0 & 0 & 0.0 & 0 & 0.0 & 15.0 & $<0.001^{* *}$ \\
\hline Total & 51 & 27 & 52.9 & 13 & 25.5 & 11 & 21.6 & & \\
\hline
\end{tabular}

$P$ value of $>0.05=$ Non-Significant $P$ value of $<0.05=$ Significant $(*) . P$ value of $<0.01=$ Highly Significant $(* *)$.

Table-4: Chi-Square statistical analysis of fusion status (xiphoid with the mesosternum) in males and females at different age groups of the study.

\begin{tabular}{|c|c|c|c|c|c|c|c|}
\hline \multirow{3}{*}{ Age group } & \multicolumn{6}{|c|}{ No of subjects showing fusion } & \multirow[b]{3}{*}{ P.value } \\
\hline & \multicolumn{2}{|c|}{ Complete } & \multicolumn{2}{|c|}{ Partial } & \multicolumn{2}{|l|}{ Absent } & \\
\hline & $\begin{array}{c}\text { Male } \\
\text { No. }(\%)\end{array}$ & $\begin{array}{l}\text { Female } \\
\text { No.(\%) }\end{array}$ & $\begin{array}{c}\text { Male } \\
\text { No. }(\%)\end{array}$ & $\begin{array}{l}\text { Female } \\
\text { No. }(\%)\end{array}$ & $\begin{array}{l}\text { Male } \\
\text { No.(\%) }\end{array}$ & $\begin{array}{l}\text { Female } \\
\text { No.(\%) }\end{array}$ & \\
\hline $30-$ & $0(0.0)$ & $0(0.0)$ & $3(30.0)$ & $2(20.0)$ & $7(70.0)$ & $8(80.0)$ & 0.605 \\
\hline $35-$ & $0(0.0)$ & $1(20.0)$ & $2(28.8)$ & $3(60.0)$ & $5(71.4)$ & $1(20.0)$ & 0.162 \\
\hline $40-$ & $5(55.6)$ & $2(28.6)$ & $3(33.3)$ & $4(57.1)$ & $1(11.1)$ & $1(14.3)$ & 0.549 \\
\hline $45-$ & $6(75.0)$ & $6(66.7)$ & $2(25.0)$ & $2(25.0)$ & $0(0.0)$ & $1(12.5)$ & 0.623 \\
\hline $50-$ & $5(71.4)$ & $5(83.3)$ & $1(14.3)$ & $1(16.7)$ & $1(14.3)$ & $0(0.0)$ & 0.628 \\
\hline $55-$ & $6(100.0)$ & $6(100.0)$ & $0(0.0)$ & $0(0.0)$ & $0(0.0)$ & $0(0.0)$ & -------- \\
\hline $60-65$ & $3(100.0)$ & $5(100.0)$ & $0(0.0)$ & $0(0.0)$ & $0(0.0)$ & $0(0.0)$ & -------- \\
\hline Total & $25(51.0)$ & $27(52.9)$ & $11(22.4)$ & $13(25.5)$ & $13(26.5)$ & $11(21.6)$ & \\
\hline
\end{tabular}


Table-5: Chi-Square statistical analysis ( $\mathrm{X}^{2}$-test) of fusion status in males ( manibrium with the body) at different age groups of the study.

\begin{tabular}{|c|c|c|c|c|c|c|c|c|c|}
\hline \multirow{3}{*}{ Age group } & \multicolumn{7}{|c|}{ No of subjects showing fusion } & \multirow{3}{*}{$\mathbf{X} 2$} & \multirow{3}{*}{ P.value } \\
\hline & \multirow{2}{*}{ No of cases } & \multicolumn{2}{|c|}{ Complete } & \multicolumn{2}{|c|}{ Partial } & \multicolumn{2}{|c|}{ Absent } & & \\
\hline & & No. & $\%$ & No. & $\%$ & No. & $\%$ & & \\
\hline $30-$ & 10 & 0 & 0.0 & 0 & 0.0 & 10 & 100.0 & 30.0 & $<0.001^{\text {** }}$ \\
\hline $35-$ & 7 & 0 & 0.0 & 0 & 0.0 & 7 & 100.0 & 21.0 & $<0.001^{\text {* }}$ \\
\hline $40-$ & 9 & 0 & 0.0 & 0 & 0.0 & 9 & 100.0 & 27.0 & $<0.001^{\text {*** }}$ \\
\hline $45-$ & 8 & 0 & 0.0 & 1 & 12.5 & 7 & 87.5 & 16.13 & $<0.001^{\text {** }}$ \\
\hline $50-$ & 6 & 1 & 16.7 & 3 & 50.0 & 2 & 33.3 & 1.5 & 0.472 \\
\hline $55-$ & 6 & 3 & 50.0 & 2 & 33.3 & 1 & 16.7 & 1.5 & 0.472 \\
\hline $60-65$ & 3 & 3 & 100.0 & 0 & 0.0 & 0 & 0.0 & 9.0 & $0,011^{*}$ \\
\hline Total & 49 & 7 & 14.3 & 6 & 12.2 & 36 & 73.5 & & \\
\hline
\end{tabular}

$P$ value of $>0.05=$ Non-Significant. $P$ value of $<0.05=$ Significant $(*) . P$ value of $<0.01=$ Highly Significant $(* *)$.

Table-6: Chi-Square statistical analysis $\left(\mathrm{X}^{2}\right.$-test) of fusion status in female (manibrium with the body) at different age groups of the study.

\begin{tabular}{|c|c|c|c|c|c|c|c|c|c|}
\hline \multirow{3}{*}{ Age group } & \multicolumn{7}{|c|}{ No of subjects showing fusion } & \multirow{3}{*}{$\mathbf{X} 2$} & \multirow{3}{*}{ P.value } \\
\hline & \multirow{2}{*}{ No of cases } & \multicolumn{2}{|c|}{ Complete } & \multicolumn{2}{|c|}{ Partial } & \multicolumn{2}{|c|}{ Absent } & & \\
\hline & & No. & $\%$ & No. & $\%$ & No. & $\%$ & & \\
\hline $30-$ & 10 & 0 & 0.0 & 0 & 0.0 & 10 & 100.0 & 30.0 & $<0.001^{* *}$ \\
\hline $35-$ & 5 & 0 & 0.0 & 0 & 0.0 & 5 & 100.0 & 15.0 & $<0.001^{* *}$ \\
\hline $40-$ & 7 & 0 & 0.0 & 1 & 14.3 & 6 & 85.7 & 13.29 & $0.001 *$ \\
\hline $45-$ & 12 & 0 & 0.0 & 3 & 25.0 & 9 & 75.0 & 15.75 & $<0.001^{* *}$ \\
\hline $50-$ & 6 & 2 & 33.3 & 4 & 66.7 & 0 & 0.0 & 6.0 & $0.049 *$ \\
\hline $55-$ & 6 & 3 & 50.0 & 3 & 50.0 & 0 & 0.0 & 4.5 & 0.105 \\
\hline $60-65$ & 5 & 5 & 100.0 & 0 & 0.0 & 0 & 0.0 & 15.0 & $<0.001^{* *}$ \\
\hline Total & 51 & 10 & 19.6 & 11 & 21.6 & 30 & 58.8 & & \\
\hline
\end{tabular}

$\mathrm{P}$ value of $>0.05=$ Non-Significant. $\mathrm{P}$ value of $<0.05=$ Significant $(*)$. $\mathrm{P}$ value of $<0.01=$ Highly Significant $(* *)$.

Table-7 : Chi-Square statistical analysis of fusion status ( manibrium with the body) in males and females at different age groups of the study.

\begin{tabular}{|c|c|c|c|c|c|c|c|}
\hline \multirow{3}{*}{ Age group } & \multicolumn{6}{|c|}{ No of subjects showing fusion } & \multirow[b]{3}{*}{ P.value } \\
\hline & \multicolumn{2}{|c|}{ Complete } & \multicolumn{2}{|c|}{ Partial } & \multicolumn{2}{|l|}{ Absent } & \\
\hline & $\begin{array}{c}\text { Male } \\
\text { No. }(\%)\end{array}$ & $\begin{array}{l}\text { Female } \\
\text { No. }(\%)\end{array}$ & $\begin{array}{c}\text { Male } \\
\text { No. }(\%)\end{array}$ & $\begin{array}{l}\text { Female } \\
\text { No. }(\%)\end{array}$ & $\begin{array}{l}\text { Male } \\
\text { No. }(\%)\end{array}$ & $\begin{array}{l}\text { Female } \\
\text { No. }(\%)\end{array}$ & \\
\hline $30-$ & $0(0.0)$ & $0(0.0)$ & $0(0.0)$ & $0(0.0)$ & $10(100.0)$ & $10(100.0)$ & ------- \\
\hline $35-$ & $0(0.0)$ & $0(0.0)$ & $0(0.0)$ & $0(0.0)$ & $7(100)$. & $5(100.0)$ & --------- \\
\hline $40-$ & $0(0.0)$ & $0(0.0)$ & $0(0.0)$ & $1(14.3)$ & $9(100.0)$ & $6(85.7)$ & 0.241 \\
\hline $45-$ & $0(0.0)$ & $0(0.0)$ & $1(12.5)$ & $3(25.0)$ & $7(87.5)$ & $9(75.0)$ & 0.493 \\
\hline $50-$ & $1(16.7)$ & $2(33.3)$ & $3(50.0)$ & $4(66.7)$ & $2(33.3)$ & $0(0.0)$ & 0.289 \\
\hline $55-$ & $3(50.0)$ & $3(500)$ & $2(33.3)$ & $3(50.0)$ & $1(16.70$ & $0(0.0)$ & 0.548 \\
\hline $60-65$ & $3(100.0)$ & $5(100.0)$ & $0(0.0)$ & $0(0.0)$ & $0(0.0)$ & $0(0.0)$ & ------- \\
\hline Total & $7(14.3)$ & $10(19.6)$ & $6(12.2)$ & $11(21.6)$ & $36(73.5)$ & $30(58.8)$ & \\
\hline
\end{tabular}




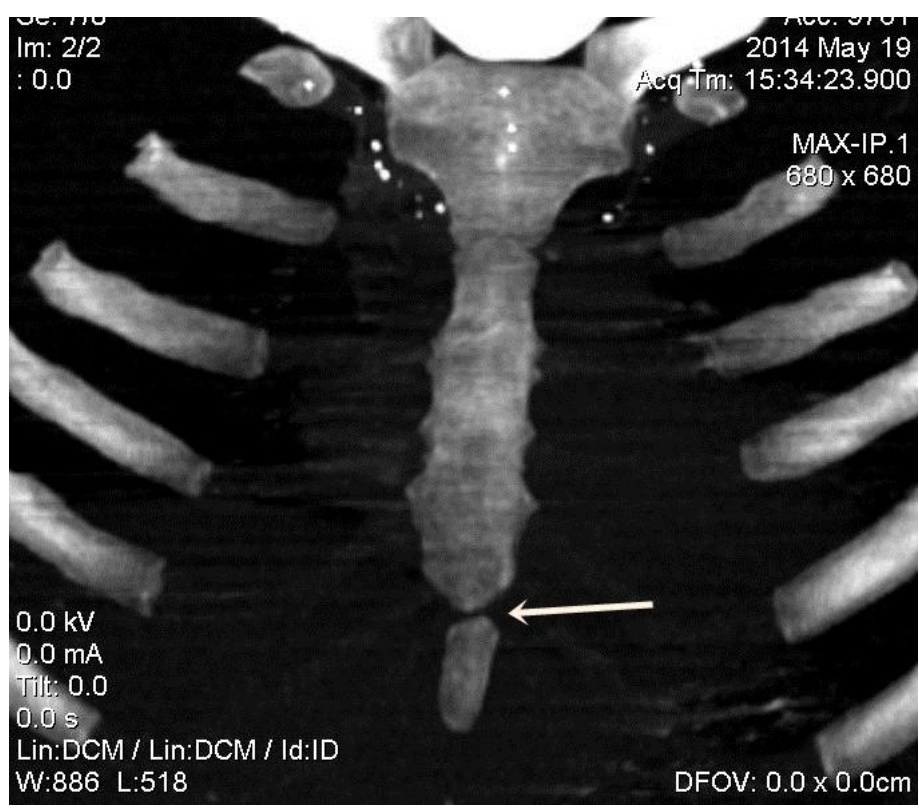

Figure -1: MIP CT Image (Frontal views) of 35 years old male showing non-fused xiphoid process and mesosternum.

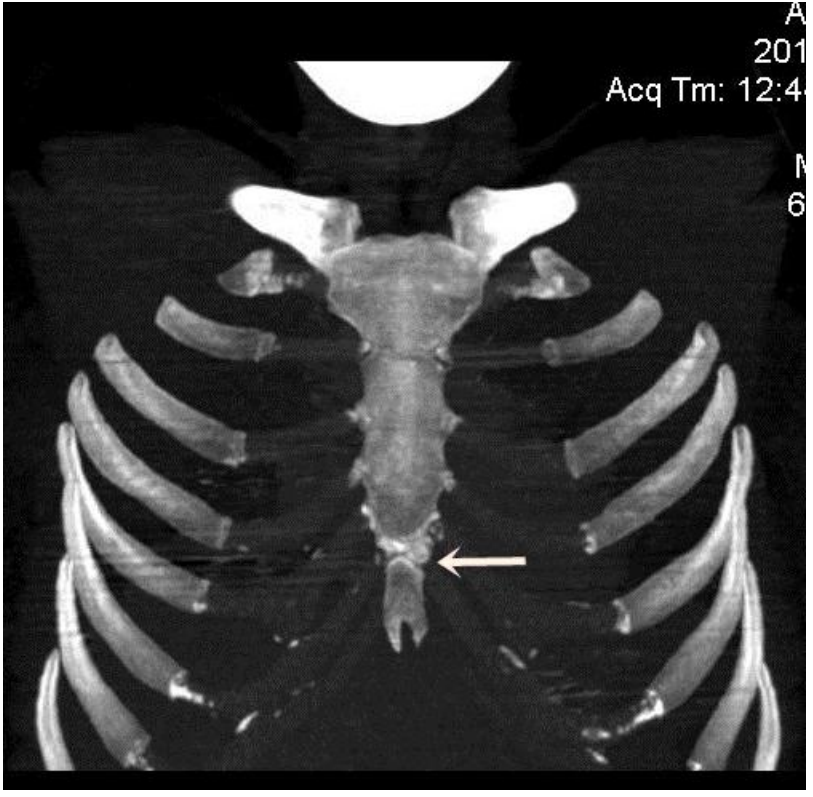

Figure -2: MIP CT image ( Frontal views) of 43 years old female showing partial fusion of xiphoid process and mesosternum

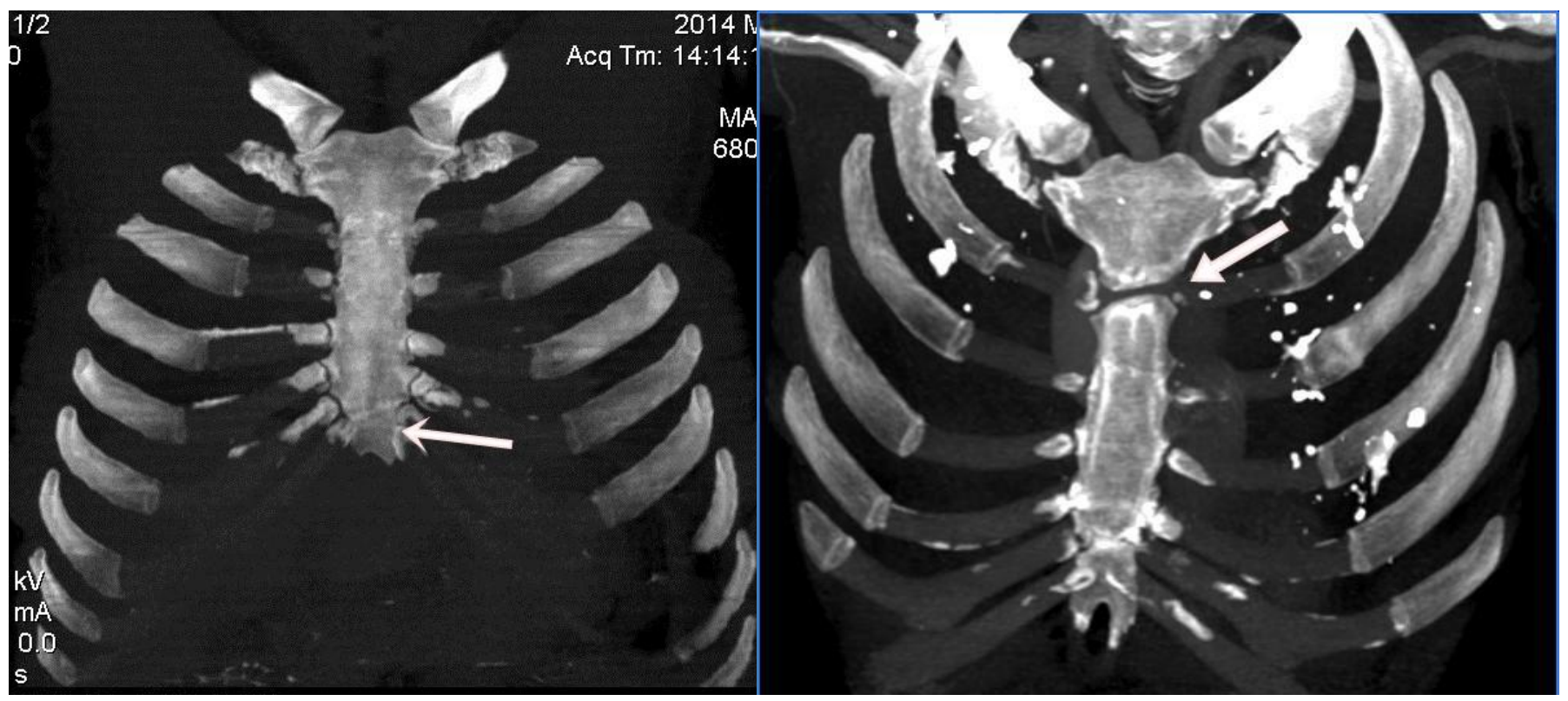

Figure -3: MIP CT image of ( Frontal views) 63 years old male showing complete fusion between xiphoid and mesosternum .
Figure -4: MIP CT Image ( Frontal views) of female 39 years showed non fusion between manibrium and mesosternum 


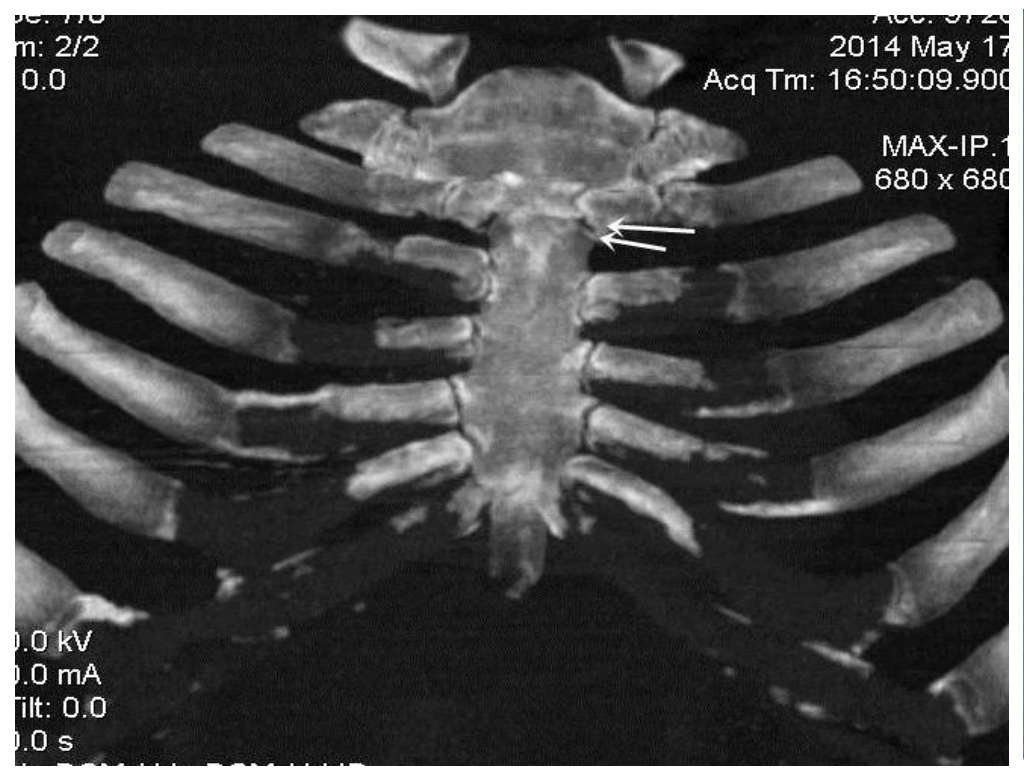

Figure -5: MIP CT Image ( Frontal views) of 47 years old male showing partial fusion between manibrium and mesosternum .

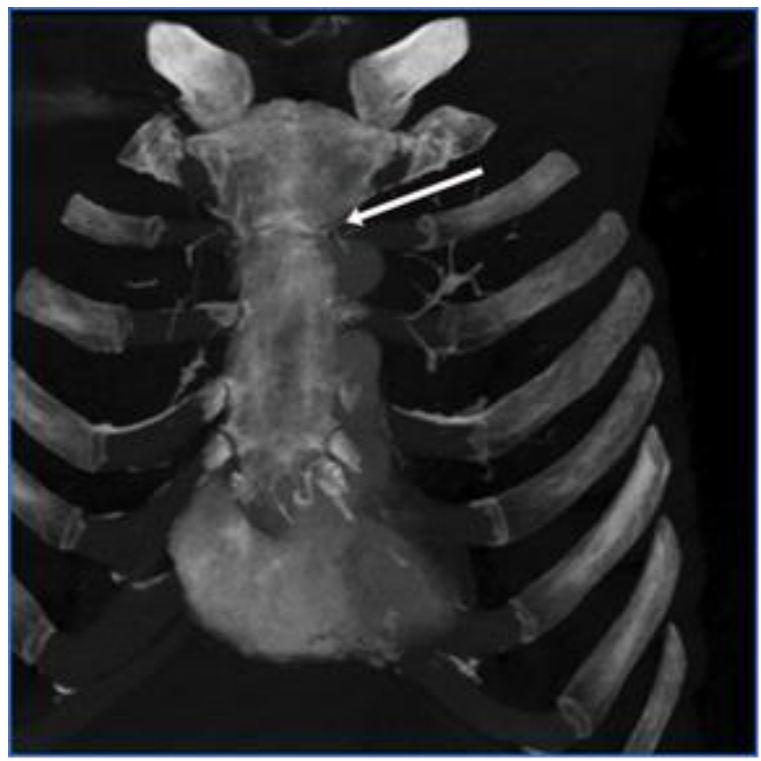

Figure -6: MIP CT image ( Frontal views) of 62 years old male showing complete fusion between manibrium and mesosternum.

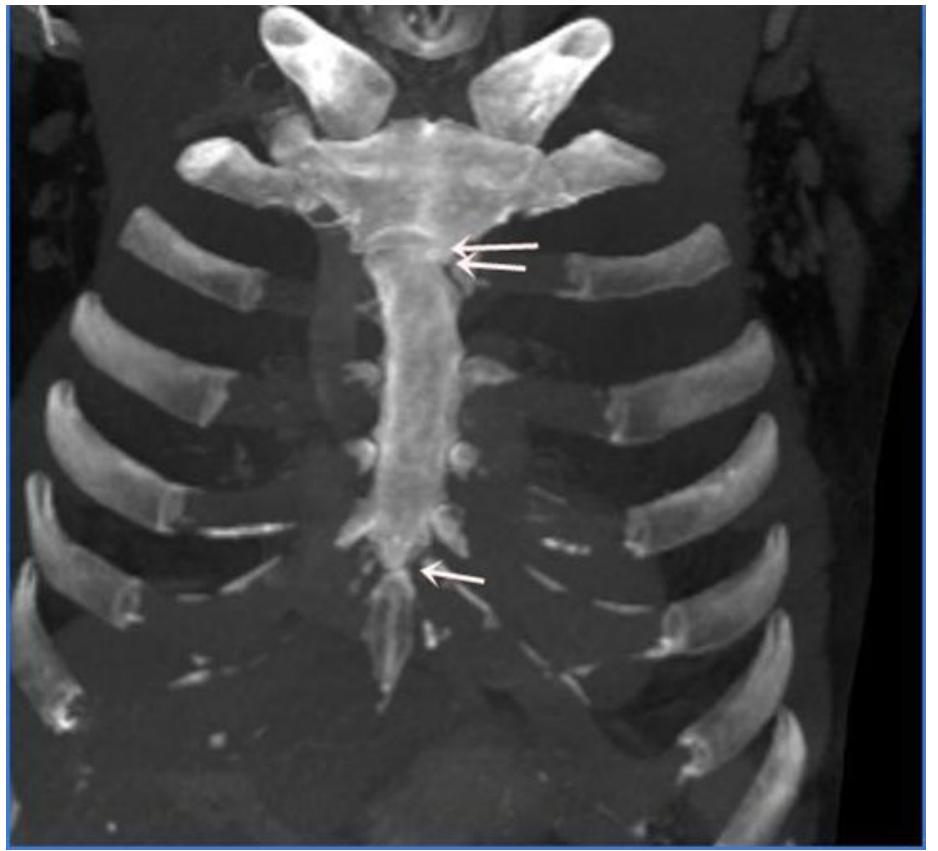

Figure -7: MIP CT image ( Frontal views) of 43 years old female showing partial fusion at both xiphoid and manibrium (arrow) as well as the manubrium with mesosternum (double arrow).

\section{Discussion}

Verification or determination of the age is prerequisite for personal identification in living as well as dead.

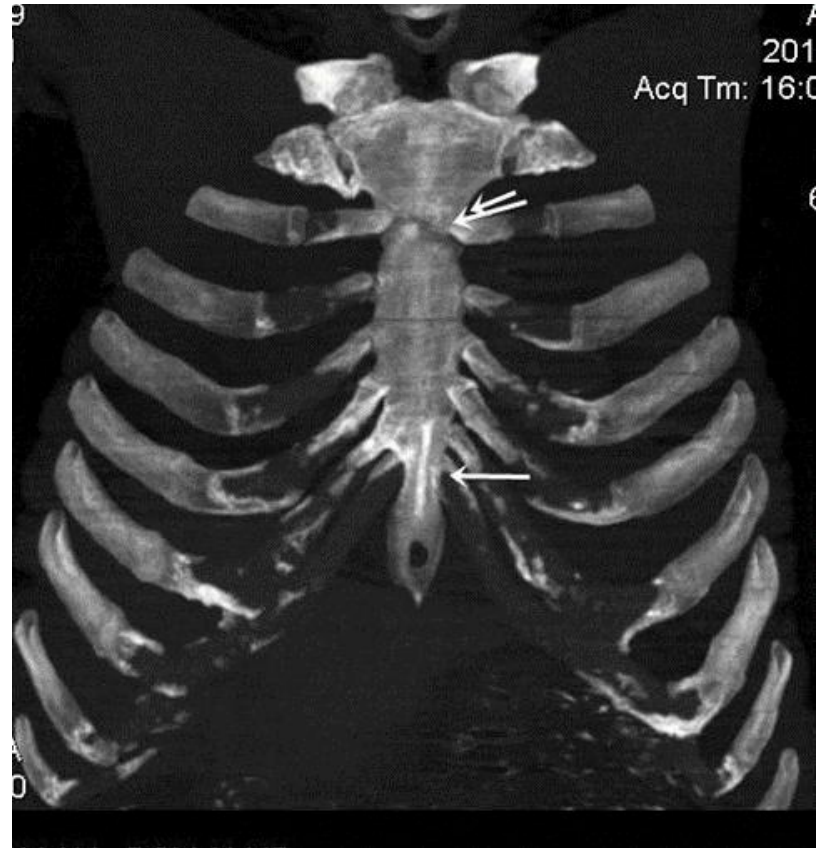

Figure -8 : MIP CT image ( Frontal views) of 65 years old male showed complete fusion at both xiphoid and manibrium (arrow) as well as the manubrium with mesosternum (double arrow).

Age estimation is one of the important tasks for a medico-legal practice (Singh and Pathak, 2013). 
There is an increasing need for some other strong criteria to accurately determine the age in middle and old age groups. Due to extreme variability in time period of closure of the sutures of cranial vault and lipping of lumbar vertebra, they cannot be considered dependable for precise age estimation. In comparison, radiological examination of sternum is easy and applicable to both dead as well as living. So, fusion of xiphisternum with body of sternum and fusion of manubrium with the body of sternum can serve as an important tool for age estimation in middle and old aged persons (Wadhawan et al., 2010).

Study of sternum as an individual parameter for determination of age and sex has been attempted by various studies. First recorded data is by Wenzel (1788), he described the difference in the ratio between the length of manubrium and that of mesosternum in both sexes. Then it was followed by Dwight (1890) and Ashley (1956) (Gautam et al., 2003).

\section{a) As regard fusion status of xiphoid process with the mesosternum in male and female groups respectively}

The result of the present study showed that, in male and female groups, the fusion of xiphoid with mesosternum began after 30 yrs of age but the fusion was not complete within 30 to 40 yrs. From 45 up to 55 yrs, closure was invariable with different degrees. From the age of 55 up to 65 yrs, all subjects showed complete fusion. It was also noticed that complete fusion between xiphoid process and mesosternum started earlier in female group than in male group (at 35 to 40 yrs \& 40 to 45 yrs respectively).

Garg et al. (2011) observed during X- ray examination of group of Indian population, that the earliest age of fusion of xiphoid process with body of the sternum was $36 \& 35$ yrs for males \& females respectively. The latest age of fusion of xiphoid process with body of the sternum was $59 \& 56 \mathrm{yrs}$ in males \& females respectively. The average age of fusion of the xiphisternum with the body of the sternum is 50.04 yrs in males \& 46.42 yrs in females. They concluded that at the age group of 40-50 years, only $50 \%$ of population is showing fusion at Xiphisternal Joint by lateral view radiography. In rest of $50 \%$ of population, still the fusion is incomplete.

Also, Wadhawan et al.( 2010) had examined 100 subjects brought to post mortem examination in the Department of Forensic Medicine Hardinge Medical College, Delhi. They concluded that the fusion between sternum and the xiphoid process is absent in all the cases up to thirty years of age and fusion of the xiphoid process with the body of sternum began after the age of thirty years. The fusion almost invariably continues up to the age of 45 years, as no sterna was
Umap et al. (2013) had conducted prospective study at Department of Radiodiagnosis Government medical College and Hospital Miraj using the utility of spiral multislice CT. They considered that the fusion of xiphoid with sternum, in both genders began after 30 years of age but it was not complete. By the age of 40 years all women showed fused xiphoid with sternum whereas in the age group of 41 to 45 years about $71.42 \%$ men had complete fusion while $28.56 \%$ had partial fusion. Since the study had included subjects up to 45 years of age therefore the maximum age at which all subjects would show complete fusion is not known. Similarly in the age group of 36 to 40 years of age, about $14.28 \%$ of men showed non-fusion. Thus it can be considered that in women the fusion occurs at 40 years while in majority of men it occurs between 41 to 45 years of age.

\section{b) As regard fusion status of manibrium with the meosternum in male and female groups respectively}

The result of the present study showed that in male group, fusion couldn't be detected from the age of 30 up to 40 yrs. Fusion began after 45 yrs of age. The fusion was invariable in the age from 50 up to $60 \mathrm{yrs}$ old. From the age of 60 to 65 yrs all subjects showed complete fusion. In female group, it was noted that fusion delayed up to $40 \mathrm{yrs}$. Partial fusion began from 40 up to 45 yrs of age. In the age from above 45 to 60 yrs the fusion was invariable. From the age of 60 to 65 yrs all subjects showed complete fusion. It was also noticed that partial fusion started earlier in female group than in male group (at 40 years \& 45 yrs respectively).

Recently, Silajiya et al. (2013) had studied xray films of group of Punjab population. The study showed that amongst males, up to 49 years of age, majority did not show even starting up of process of fusion between manubrium and body of the sternum. Between the ages of 50 to 58 years, a high number of subjects were showing that the gap between joint began to decrease. At the ages of 59 and above plenty of cases are showing complete fusion at manubriosternal joint. This suggest that the fusion at manubriosternal starts at the age of 50 years and it completes after the age or 59 years but the exact age for complete fusion at manubrio-sternal joint could not be defined. Amongst females, the cases showing partial fusion are seen increasing from the age of 54 years and complete fusion after the age of 64 years.

Further more Gautam et al. (2003) had examined 100 sternum, obtained from the cadavers brought for medico-legal post-mortem examination at Ahmedabad. They found that all the cases below the age of the 40 years did not show either complete or partial fusion of the manubrium and the body of the sternum. No case has been recorded with complete fusion below 50 years of age. Above 55 years fusion is complete/partial in all. 


\section{Conclusion}

From the previous results it can be concluded that applicating multi-slice CT- based age diagnostics assessment of the degree of fusion of the xiphoid process and manubrium with mesosternum could be helpful in estimation of age. The fusion of the xiphoid process with the mesosternum began after the age of thirty. The fusion was present in uneven degrees up to the age of forty-five. In most of subjects the fusion is complete after the age of fifty. The fusion of the manubrium with the mesosternum began after the age of forty. The fusion was present in varying degrees in subjects above fifty five years. Complete fusion, when present, occurs after the age of fifty. All these data could be helpful in determination of age from sternal bone.

Owing to the findings of the present and referred studies, it is recommended to do further studies using the parameters mentioned in this study on greater sector of the Egyptian population to get a radiometric standard specific for them so as to achieve reference data usable in age estimation practice.

\section{ReFrences}

Ashley G T (1956) :The human sternum - The influence of sex \& age on its measurements. Journal of Forensic Mediciene. 3: 27- 43.

Atal D K, Murari A, Rani Y et al., (2008): Gender differentiation from sternum a postmortem metric study. International Journal of Medical Toxicology \& Legal Medicine. 11(2):53-58.

Dwight T (1890): Sternum as an index of sex, height, and age. Journal of anatomy and physiology. 24(4): 527.

Garg A , Goyal N and Gorea R K (2011): Radiological Age estimation from Xiphisternal joint in living person. J Indian Acad Forensic Med.33:27-29.

Gautam R S , Shah G V , Jadav $H$ et al., (2003):The human sternum-as

an index of age and sex. J Anat Soc India. 52(1): 203.

Gupta P , Rai H, Kalsey G et al., (2007). Age determination from sternal ends of the Ribsan autopsy study. Journal of Indian Academy of Forensic Medicine. 29(4): 94-97.

Kaneriya D , Umarvanshi B, Patil D et al., (2013): Age determination from fusion of the sternal elements. Int. J. Basic Applied Med. Sci, 3(2), 22-9.

Menezes, R G, Nagesh K R, Monteiro, F. N et al., (2011): Estimation of stature from the length of the sternum in South Indian females. Journal of forensic and legal medicine.18(6): 242-245.

O'Donnell C, Iino M , Mansharan, K et al., (2011): Contribution of postmortem multidetector CT scanning to identification of the deceased in a mass disaster: experience gained from the 2009 Victorian bushfires. Forensic science international. 205(1): 15-28.

Silajiya D A, Khubchandani H T, Soni S N et al., (2013): Radiological Age Estimation From Sternum. National Journal of Integrated Research in Medicine. 4(4):108-114.

SinghJ and Chavali K H (2011): Age estimation from clavicular epiphyseal union sequencing in a Northwest Indian population of the Chandigarh region. Journal of forensic and legal medicine. 18(2): 82-87.

Singh J and Pathak R K (2013): Sex and age related non-metric variation of the human sternum in a Northwest Indian postmortem sample: A pilot study. Forensic science international. 228(1): 181.

Tailor C I, Silajiya D, Govekar G et al., (2013): Age Determination by Gross and Radiological Aspect of Sternum. J Indian Acad Forensic Med. Jan-March, 35(1):0971-0973.

Tangmose S, Jensen K E and Lynnerup N (2013): Comparative study on developmental stages of the clavicle by postmortem MRI and CT imaging. Journal of Forensic Radiology and Imaging. 1(3): 102-106.

Umap R, Bardale R and Shriramwar, P. Utility of spiral multislice CT scan in estimation of age from sternum: A preliminary study. Journal of Forensic Medicine, Science and Law. A Journal of Medicolegal Association of Maharashtra. 22( 2):1-6.

Wadhawan M , Murari A and Naik S K (2010): Correlation between age and degree of fusion involving sternal joints. Indian Journal of Forensic Medicine and Pathology. 3(1).

Wenzel J (1788): Cited by Ashley G.T. (1956) : A comparison of human and anthropoid mesosterna. American Journal of Physical Anthropology. $\quad 3:$ 449-461. 


\section{الملخص العربحى}

\section{استخدام الأشعة المقطعية متعددة المقطع فى تقدير العمر اعتمادا على حالة إلتحام أجزاء عظام القص فى مجموعة من المصريين}

\section{ايمان أحمد علاء الدين و هبة السيد مصطفى و سامح صابر'}

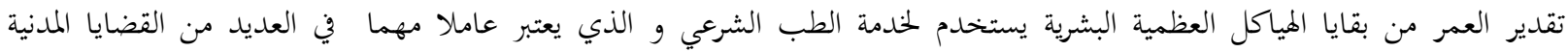

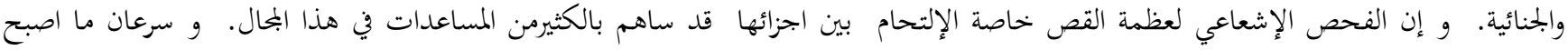

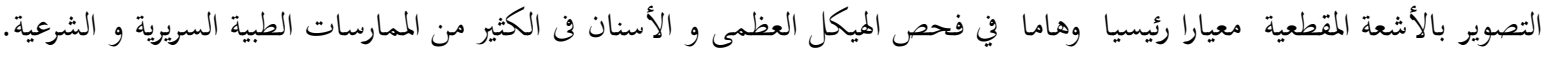

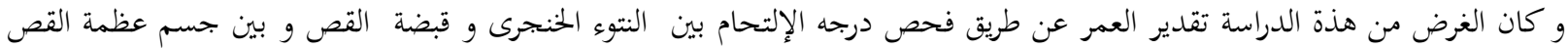
باستخدام الأشعة المقطعية.

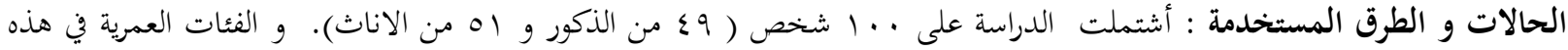

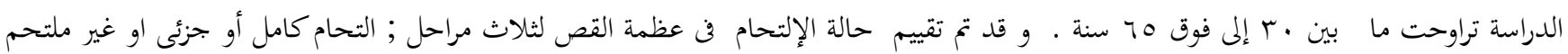
باستخدام التصوير بالأشعة المقطعية.

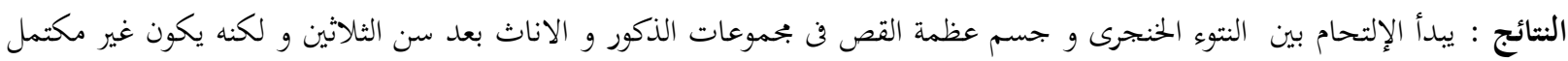

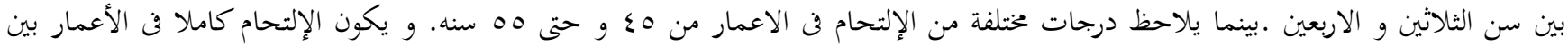

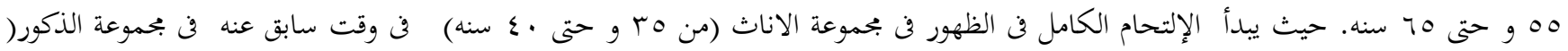

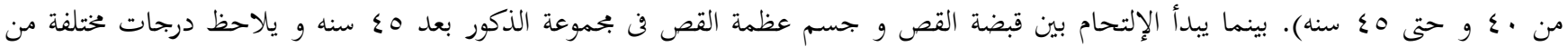

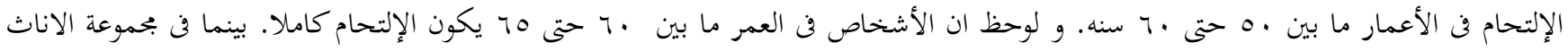

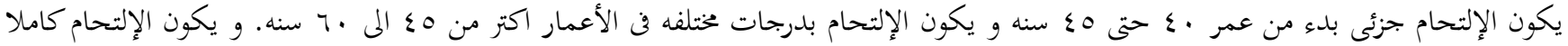

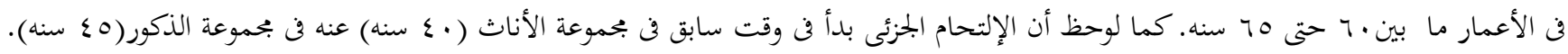

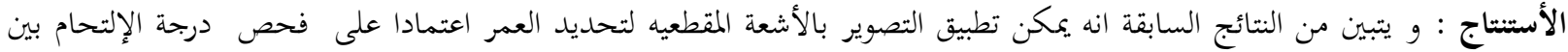

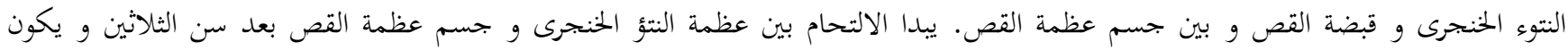

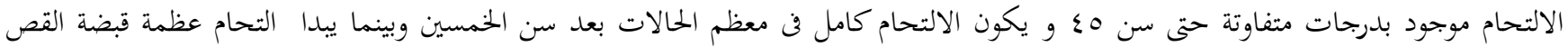

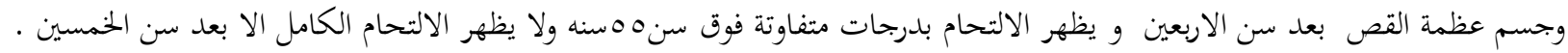

